\title{
Doxycycline encapsulated in $\beta$-cyclodextrin for periodontitis: a clinical trial
}

Vivianne Carvalho da Cunha TRAJANO(a) Cláudia Borges BRASILEIRO(b) Jonathas Antônio de Souza HENRIQUES(b) (ic) Luís de Miranda COTA ${ }^{(b)}$ (i) Célia Regina LANZA ${ }^{(b)}$ Maria Esperanza CORTÉS(a) (D)

(a) Universidade Federal de Minas Gerais UFMG, Faculty of Dentistry, Department of Restorative Dentistry, Belo Horizonte, MG, Brazil.

(b) Universidade Federal de Minas Gerais UFMG, Faculty of Dentistry, Department of Oral Clinical, Surgery and Pathology, Belo Horizonte, MG, Brazil.

Declaration of Interests: The authors certify that they have no commercial or associative interest that represents a conflict of interest in connection with the manuscript.

Corresponding Author: Maria Esperanza Cortés E-mail:mecortes@ufmg.br

Submitted: June 18, 2018

Accepted for publication: April 8, 2019 Last revision: October 29, 2019
Abstract This clinical trial compared the efficacy of doxycycline (DOX) in $\beta$-cyclodextrin (DOX)/ $\beta C D$ ) with DOX- alone in gel on thirty-three subjects with periodontitis. Patients were randomized to group $1 \mathrm{GI} ; 10 \% \mathrm{DOX}+$ scaling and root planning (SRP); group 2 (GII (10\% DOX / $\beta-C D+S R P)$, and group 3 (GIII; SRP). Gels were applied in $G I$ and $G I$ at baseline (TO) and 30 days later (T1). Periodontal Probing Depth (PPD), Clinical Attachment Level (CAL), Bleeding on Probing (BOP) and Visible Plaque Index (VPI) were evaluated at (TO), 30 days (T1) and 60 days after TO (T2). Bone density was analyzed after 18 months (T3). GIl showed the most significant reduction of PPD $(2.62 \mathrm{~mm} ; \mathrm{p}<0.003)$, and greatest gain in CAL $(2.54 \mathrm{~mm} \mathrm{p} \mathrm{<0.003)} \mathrm{at} \mathrm{T2.} \mathrm{BOP} \mathrm{and} \mathrm{the} \mathrm{VPI} \mathrm{had} \mathrm{a}$ strong reduction in all groups at T2 ( $p<0.05)$, both decreased by $\geq 5$ times and 2 times, respectively, in all groups at T1. Bone density increased in all groups in radiographs (T3). The use of DOX encapsulated in $\beta-C D$ gel with SRP resulted in significant improvements in clinical periodontal parameters; such molecular inclusion of doxycycline into $\beta-C D$ in gel for local application is relatively simple and useful in dentistry.

Keywords: Periodontitis; Doxycycline; Gels; Beta-cyclodextrin.

\section{Introduction}

Antibiotics have been used in periodontal treatment to minimize the failure of mechanical debridement by scaling and root planing (SRP), which is considered to be the gold standard procedure. ${ }^{1}$ The slowrelease application of antimicrobial agents in the periodontal pockets provides constant drug release to eliminate pathogens and modulate the inflammatory response, thereby limiting tissue destruction. Studies have demonstrated the efficacy and benefits of slow-release systems compared with systemic drug administration. ${ }^{2}$

Doxycycline (DOX) acts on Gram-positive and Gram-negative bacteria and on specific periodontal pathogens. ${ }^{3}$ Its main antibiotic mechanism of action is the inhibition of protein synthesis. ${ }^{4}$ It presents anti-inflammatory properties through direct inhibition of the activity of matrix metalloproteinases, which participate in periodontal tissue destruction ${ }^{5}$ and are considered to be the most potent anti-collagenase 
agents. ${ }^{6,7}$ DOX also has an osteogenic effect, as it promotes bone tissue formation through the activation of osteoblasts and inhibition of bone resorption. ${ }^{8}$ At subtherapeutic levels, DOX has beneficial effects on bone tissue repair processes and modulation of the host response. ${ }^{4}$ Thus, the non-antimicrobial properties of DOX may contribute to its effectiveness in the treatment of periodontitis. ${ }^{9}$

The use of a gel to apply a drug in the periodontal pocket ensures longer retention of the drug in place, which prolongs its effects. ${ }^{2,6,10}$ However, the inflammation process in periodontitis increases the renewal rate of gingival crevicular fluid, which leads to more rapid diffusion of the drug from the delivery device. ${ }^{11}$ Thus, an important goal in the development of drug delivery systems is to maximize adhesiveness. ${ }^{12}$

Ten-percent DOX gel has been used in the treatment of periodontitis and has been proven to more effectively reduce the periodontal probing depth (PPD) and improve the clinical attachment level (CAL) compared with SRP alone, thereby improving the quality of life of individuals with periodontitis. ${ }^{13,14,15}$ However, Garrett et al. ${ }^{16}$ reported that the treatment of moderate to severe periodontitis with $10 \%$ DOX was only as effective as SRP.

Thus, to improve treatment efficacy and prevent physicochemical and biological degradation of drugs, molecular inclusion strategies, including those employing cyclodextrins, have been investigated. Beta-cyclodextrin $(\beta-C D)$ has advantages such as its utility in drug carrier systems; increased solubility; bioavailability; ability to provide aqueous stability for lipophilic drugs; and control of the release profiles of water-soluble drugs, such as DOX. These advantages serve to increase therapeutic efficacy and reduce local and systemic adverse effects. ${ }^{17}$

Thus, the purpose of this study was to assess the clinical outcomes following the treatment of periodontitis with $10 \%$ DOX encapsulated in $\beta$-CD gel, and with pure 10\% DOX in the gel. The hypothesis was that the inclusion compound would increase the mucoadhesiveness of the gel and the encapsulation of DOX in $\beta-C D$, enhancing the drug's local effects.

\section{Methodology}

\section{Study design and sample}

This randomized blinded clinical trial was designed to compare the effects of $10 \%$ DOX gel with those of $10 \%$ DOX gel included in $\beta$-CD as adjunctive topical agents for the treatment of periodontitis with SRP. The examiner and participants were blinded to the type of gel applied. The Research Ethics Committee of the Federal University of Minas Gerais approved this study ( $\left.\mathrm{N}^{\mathrm{o}} 790.967\right)$, which was conducted in accordance with the Helsinki Declaration. The trial is registered at ClinicalTrials.gov ( $\mathrm{N}^{\circ}$ RBR-243GF6).

Participants were selected in the Faculty of Dentistry, Federal University of Minas Gerais (UFMG), and signed a free informed consent form. Eligibility was determined by periodontal clinical evaluation and medical histories obtained at screening visits. The inclusion criteria were: a) age 20-45 years; b) diagnosis of periodontitis according to the criteria established by the American Academy of Periodontology; 18 and c) contralateral quadrants containing at least one molar with PPD $\geq 5 \mathrm{~mm}, \mathrm{CAL} \geq 6 \mathrm{~mm}$, and bleeding on probing (BOP). The exclusion criteria were: a) systemic disease, such as hypertension, diabetes mellitus, osteoporosis, or immunodeficiency; b) requirement for antibiotic prophylaxis before periodontal treatment; c) use of systemic antibiotics or controlled or continuoususe drugs in the previous 6 months; d) pregnancy or active lactation; e) allergy to DOX or periodontal dressing; and f) receipt of surgical or non-surgical periodontal therapy in the previous 6 months.

Based on the analysis of periodontograms, two molars in contralateral quadrants were selected in each individual. Third molars and elements with furcation and endo-periodontal lesions were excluded. For each molar, measurements were taken at four sites [buccal (B), lingual (L), mesial (M), and distal (D)], and the sites with the greatest PPD were selected.

The sample size was calculated using the Statistical Package for the Social Sciences (version 19.0 for Windows; IBMSPSS, Armonk, USA), which indicated that a minimum of 24 individuals (8 per group) was required for analysis with a significance level of $5 \%$. Assuming that $20 \%$ of individuals would not complete the treatment, we selected a total of 36 individuals (12 
per group). One subject from group 1 (GI) and two subjects from group 3 (GIII) dropped out at T0. Thus, 33 subjects were distributed by simple randomization into three independent groups: GI (10\% DOX gel + SRP), group 2 (GII; $10 \%$ DOX included in $\beta$-CD gel + $\mathrm{SRP})$, and GIII (SRP alone). They were evaluated at the beginning of the study (T0), at the first application of the gel (T1, 30 days after T0), and at the second application of the gel (T2, 60 days after T0). Four sites (B, L, M, and D) of the two molars in each subject were evaluated (total, 264 sites; GI, $\mathrm{n}=88$; GII, $\mathrm{n}=96$; GIII, $n=80$ ). Statistical powers of $84 \%$ for the group factor, and $96 \%$ for the time factor and group $\times$ time interaction were considered, with a significance level of $5 \%$ and effect magnitudes of 0.79 for the group factor, and 1.12 for the time factor and group $\times$ time interaction (estimated from values reported by $\mathrm{Sato}^{19}$ ). The main determinant of periodontitis and sample size was $\mathrm{CAL} \geq 6 \mathrm{~mm}^{19}$

\section{Periodontal procedures}

To calibrate the researcher with an expert examiner in the clinical examination and periodontal treatment procedures, six subjects were enrolled in a pilot study. Pilot study measurements were repeated within a 1 -week interval, and $\kappa$ values were calculated to determine the baseline efficacy of antimicrobial application (satisfactory, $\kappa>0.8$ ). The two examiners were also trained in the evaluation of radiographic parameters. All subjects who participated of pilot and main study received oral hygiene instructions, including those on brushing technique and interdental cleaning. They underwent plaque control by coronary polishing with prophylactic paste and a Robinson brush until visible plaque indices (VPIs) $<20 \%$ were achieved. Subjects received verbal and written guidelines and maintained self-standard for oral hygiene (brushing and flossing).

The following periodontal clinical parameters were evaluated: Visible plaque, present or absent ${ }^{21}$, measurement of PPD and CAL, and BOP (present or absent, was recorded 10 seconds after probing). ${ }^{20}$ Then, SRP was performed using hand instruments, with the removal of supra- and subgingival plaque and calculus. The procedure was performed to obtain smoothness of the root surfaces. The same professional performed clinical and periodontal evaluation and treatment of all subjects at the three experimental timepoints in the following sequence: VPI annotation, followed by removal of supragingival biofilm and evaluation of clinical parameters (PPD, CAL, and BOP). At T0, SRP was performed and initial molar bitewing X-rays were taken in all subjects, followed by the first gel application to the study teeth in GI and GII. At T1, SRP was performed in all subjects and the second gel application was performed in GI and GII. At T2, SRP was performed and molar bitewing $\mathrm{X}$-rays were taken in all subjects. After 18 months (T3), final X-rays were taken.

The tubes containing the 10\% DOX and 10\% DOX- $\beta-C D$ gels were distinguished by yellow and green labels, respectively. Only the pharmacist who prepared and conditioned the gels knew which type of gel was indicated by each color; the two gels were similar in color, smell, and taste. The gel was applied through a syringe to the base of the periodontal pocket until it reached the gingival margin. Excess gel was removed with a curette. Then, a light-cured resin dam was applied and polymerized for $40 \mathrm{~s}$ to seal the gel in the pocket. The subjects were instructed to avoid hard and sticky foods, not to touch the area with the tongue or finger, to maintain oral hygiene, and to report any pain, swelling, or other adverse effect. Figure 1 is a flow chart of the study.

\section{Radiographic analysis}

Digital interproximal images of the posterior areas of all subjects were obtained at the Radiology Department of the UFMGSchool of Dentistry. The same professional took all radiographs using the parallelism technique. No additional images were acquired. Two specialists blinded to treatment allocation conducted the final evaluation by performing a fractal analysis of radiographic bone density. Two rectangular regions of interest (ROIs; $90 \times 30$ pixels, following a previous study $^{21}$ ) were selected in two different areas of the maxillary posterior interdental bone for this analysis, excluding the tooth roots and periodontal space. The average of the values of two ROIs was used to calculate the average fractal dimension for each subject, to discriminate the trabecular integrity alterations induced by periodontitis, using the box counting 


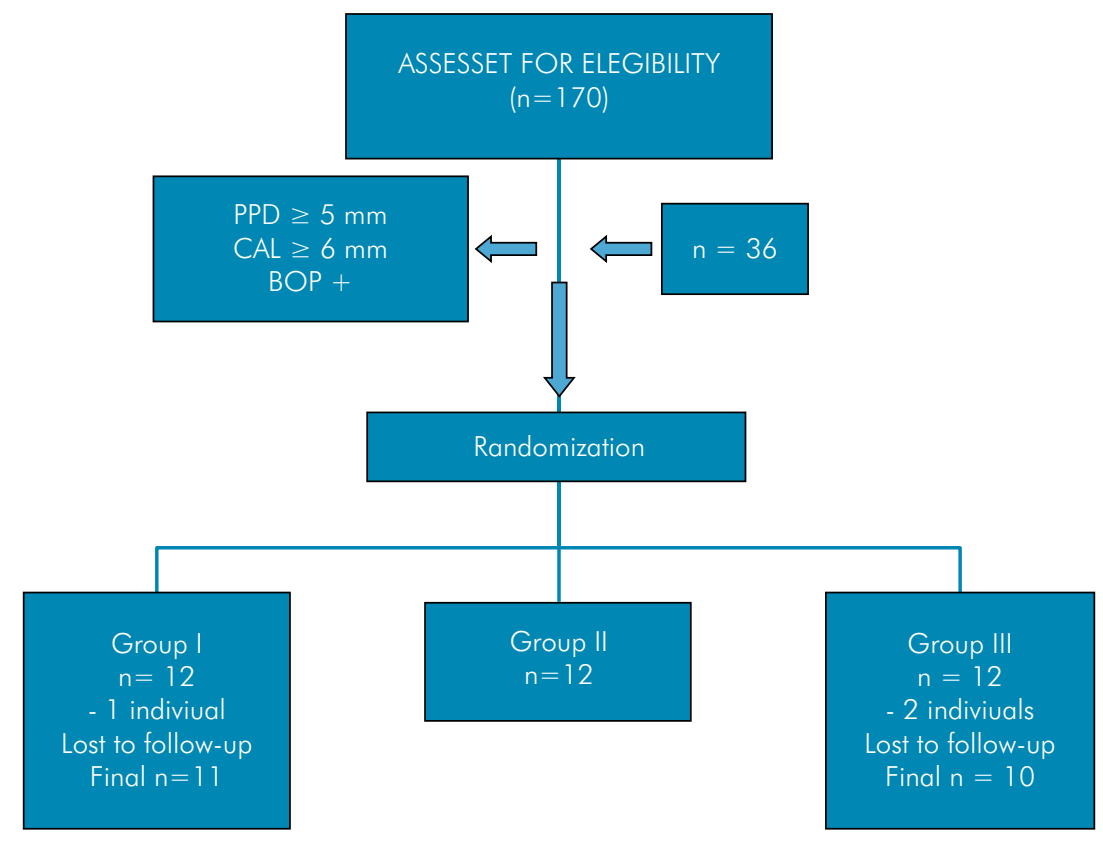

Figure 1. Flow chart of the study.

method described by White and Rudolph..$^{22,24}$ All image analysis was performed using ImageJ software (v.1.51j8; National Institutes of Health, Bethesda, USA). 200 ROIs were duplicated using the Gaussian filter blurred with a diameter of 35 pixels. After subtraction of the blurred image from the original image, an image with an average gray value of 128 pixels was obtained at the end of this procedure.

\section{Statistical analysis}

All data were analyzed using the program Statistical Package for Social Sciences, version 19.0 for Windows (SPSS, IBM, Armonk, USA). The parameters were analyzed by the arithmetic mean of the sites of both teeth selected for each subject, in each time, for comparison of treatments: GI - SRP + 10\% DOX GEL; GII - SRP + $10 \%$ DOX $/ \beta$-CD GEL and GIII - SRP. The comparison within each group was determined by Analysis of Variance technique by Blocks (ANOVA). The level of significance was $5 \%(p<0.05)$. In the comparison among groups were performed by the $t$ Test and the nonparametric Friedman Test, depending on the data distribution. Considering 3\% $(p<0.003)$. For non-numeric variables (BOP and VPI) were used Test Q-Square and Correspondence Analysis, 5\% $(p<0.05)$. In the radiographic analysis, the mean of the two ROIs was used to calculate mean FD for each participant over time. ANOVA was used for the comparison of the FDs of the groups $(p<0.05)$. The site was the unit of analysis adopted and the main outcome was CAL.

\section{Results}

This study involved 33 subjects with periodontitis [9 (27\%) men and 24 (73\%) women followed through T3. The characteristics of the patients are summarized in Table 1. At T0, the means of the clinical parameters investigated were similar among groups, indicating that randomization was effective. No adverse reaction to the treatments was reported.

\section{Periodontal probing depth}

PPD values for all group's at timepoints are shown in Table 2. At T0, the average PPD was $4.8 \pm 0.92 \mathrm{~mm}$, with no significant difference among groups. The mean reductions of the PPD values were $3.75 \pm 0.64 \mathrm{~mm}$ at $\mathrm{T} 1$ and $3.16 \pm 0.52 \mathrm{~mm}$ at $\mathrm{T} 2$. PPD reductions within GI and GII after the first and second applications were significant $(p<0.05)$. In the comparison of mean 
Table 1. Epidemiological characteristics of the patients and mean of the initial PPD and CAL according with protocol analysis.

\begin{tabular}{lccc}
\hline \multirow{2}{*}{ Groups } & & GI & GIII \\
\cline { 2 - 4 } & $10 \%$ DOX gel & $10 \%$ DOX / $\beta$-CD gel & SRP \\
\hline N Subjects 33 & 11 & 12 & 10 \\
N Sites 264 & 88 & 96 & 80 \\
Age (years) minimum/maximum & $20 / 42$ & $35 / 43$ & $37 / 45$ \\
Gender (male/female) & $01 / 10$ & $05 / 07$ & $03 / 07$ \\
Initial PPD (mm) & $4.70 \pm 1.29$ & $5.11 \pm 0.71$ & $4.88 \pm 0.77$ \\
Initial CAL (mm) & $6.13 \pm 0.99$ & $6.09 \pm 0.67$ & $6.0 \pm 0.67$ \\
\hline
\end{tabular}

Values are presented as mean \pm standard deviation. Significance within each group $(p<0.05)$ and among the groups $(p<0.003)$. The values presented refer to the mean values of the site evaluated in millimeters. PPD: Periodontal Probing Depth; CAL: Clinical attachment level.

Table 2. Comparison of PPD within each group and among groups of 10\% DOX gel and scaling and root planning (SRP) (GI), 10\% DOX: $\beta$-cyclodextrin gel and SRP (GII) and SRP alone (GIII), at different time intervals: T0 (Baseline), T1 (30 days), T2 (60 days).

\begin{tabular}{|c|c|c|c|}
\hline \multirow{2}{*}{ Clinical parameter } & \multicolumn{2}{|c|}{ Gl } & \multirow{2}{*}{$\begin{array}{l}\text { GIII } \\
\text { SRP }\end{array}$} \\
\hline & 10\% DOX gel & $10 \% \mathrm{DOX} / \beta-\mathrm{CD}$ gel & \\
\hline \multicolumn{4}{|c|}{ Periodontal Probing Depth (PPD) } \\
\hline T0 (Baseline) & $4.70 \pm 1.29$ & $5.11 \pm 0.71$ & $4.88 \pm 0.77$ \\
\hline T1 (30 days) & $3.76 \pm 0.9 a$ & $3.18 \pm 0.63^{a}$ & $4.40 \pm 0.4$ \\
\hline T2 (60 days) & $3.18 \pm 0.72$ & $2.49 \pm 0.4$ & $3.81 \pm 0.46$ \\
\hline$\Delta \mathrm{TO}-\mathrm{T} 2$ & $1.52 \pm 0.77^{a}$ & $2.62 \pm 0.31^{b}$ & $1.07 \pm 0.31^{a}$ \\
\hline \multicolumn{4}{|c|}{ Clinical attachment level (CAL) } \\
\hline T0 (baseline) & $6.13 \pm 0.99$ & $6.09 \pm 0.67$ & $6.00 \pm 0.67$ \\
\hline T1 (30 days) & $5.19 \pm 0.7$ a) & $4.25 \pm 0.73^{a}$ & $5.51 \pm 0.58$ \\
\hline T2 (60 days) & $4.61 \pm 0.63$ & $3.55 \pm 0.67 a$ & $4.95 \pm 0.58$ \\
\hline$\Delta \mathrm{TO}-\mathrm{T} 2$ & $1.52 \pm 0.36^{b}$ & $2.54 \pm 0.00^{b}$ & $1.05 \pm 0.09 a$ \\
\hline \multicolumn{4}{|c|}{ Bleeding on probing (BOP) } \\
\hline TO & 91 & 92 & 90 \\
\hline $\mathrm{T} 1$ & 59 & 50 & 55 \\
\hline $\mathrm{T} 2$ & 11 & 8 & 15 \\
\hline D TO-T2 & $80^{\circ}$ & $84^{a}$ & $75^{a}$ \\
\hline \multicolumn{4}{|c|}{ Visible plaque index (VPI) } \\
\hline TO & 77 & 79 & 80 \\
\hline $\mathrm{T} 1$ & 14 & 13 & 10 \\
\hline $\mathrm{T} 2$ & 6 & 8 & 5 \\
\hline$\Delta$ T0-Т2 & $71^{\circ}$ & $71^{a}$ & $71^{a}$ \\
\hline
\end{tabular}

Values are presented as mean \pm standard deviation. ${ }^{a}$ Significance within each group $(p<0.05)$ and ${ }^{b}$ among the groups $(p<0.003)$. The values presented refer to the mean values of the site evaluated in millimeters. PPD: Periodontal Probing Depth, CAL: clinical attachment level, BOP: bleeding on probing, VPI: visible plaque index, SRP: scaling and root planning.

differences $(\Delta \mathrm{T} 0-\mathrm{T} 2)$ among groups, all $\mathrm{T} 2$ values were lower than T0 values $(p<0.003)$ indicating that there was a gain of the periodontal health even with SRP. GII showed the greatest reduction among groups $(2.62 \pm 0.31 \mathrm{~mm}, \mathrm{p}<0.003)$ and within each group $(\mathrm{p}<0.05)$.
The evaluations of the reduction of PPD values obtained by sites expressed as percentages according to categories: 4,5 to 6 and $>6 \mathrm{~mm}$ are set out in Table 3. Initially, PPD was shallow ( $4 \mathrm{~mm}$ ) in $44 \%$ of the pockets, moderate ( 5 to $\leq 6 \mathrm{~mm}$ ) in $42 \%$ of pockets, and deep (> $6 \mathrm{~mm}$ ) in 10\% (GIII), $14 \%$ (GI), and $20 \%$ 
Table 3. Reduction values obtained of periodontal probing depth (PPD) and evaluation by sites and percentage according to PPD categories after treatment with 10\% DOX gel and scaling and root planning (SRP) (GI), 10\% DOX: $\beta$-cyclodextrin gel and SRP (GII) and SRP alone (GIII), at TO (Baseline), T1 (30 days), T2 (60 days).

\begin{tabular}{|c|c|c|c|c|c|c|c|c|c|}
\hline \multirow{3}{*}{ Periodontal Probing Depth (PPD) } & \multicolumn{9}{|c|}{ Percentage of number of sites analyzed } \\
\hline & \multicolumn{3}{|c|}{$\mathrm{Gl}$} & \multicolumn{3}{|c|}{ GII } & \multicolumn{3}{|c|}{ GIII } \\
\hline & TO & $\mathrm{T} 1$ & T2 & TO & $\mathrm{T} 1$ & T2 & TO & $\mathrm{T} 1$ & $\mathrm{~T} 2$ \\
\hline $4 \mathrm{~mm}$ & 54 & 78 & $93^{\circ}$ & 43 & 83 & $97^{b}$ & 37 & 50 & $73^{\circ}$ \\
\hline 5 to $\leq 6 \mathrm{~mm}$ & 32 & 17 & 5 & 37 & 14 & 2 & 52 & 50 & 26 \\
\hline$>6 \mathrm{~mm}$ & 14 & 4 & 1 & 20 & 2 & 0 & 10 & 0 & 0 \\
\hline Number of Sites & 88 & 88 & 88 & 96 & 96 & 96 & 80 & 80 & 80 \\
\hline
\end{tabular}

aSignificance within each group $(p<0.05)$ and bamong the groups $(p<0.003)$. PPD: Periodontal Probing Depth, SRP: scaling and root planning.

Table 4. Gain values obtained from CAL and evaluation by sites expressed as a percentage according to categories after treatment with 10\% DOX gel and scaling and root planning (SRP) (G1), 10\% DOX: $\beta$-cyclodextrin gel and SRP (GII) and SRP alone (GIII).

\begin{tabular}{|c|c|c|c|c|c|c|c|c|c|}
\hline \multirow{3}{*}{ Clinical attachment level (CAL) } & \multicolumn{9}{|c|}{ Values expressed as percentage from number of sites analyzed } \\
\hline & \multicolumn{3}{|c|}{ GI } & \multicolumn{3}{|c|}{ GII } & \multicolumn{3}{|c|}{ GIII } \\
\hline & TO & $\mathrm{T} 1$ & T2 & TO & $\mathrm{T} 1$ & T2 & TO & $\mathrm{T} 1$ & $\mathrm{~T} 2$ \\
\hline $4 \mathrm{~mm}$ & 7 & 24 & $49^{a}$ & 4 & 57 & $85^{b}$ & 7 & 16 & $32^{b}$ \\
\hline $5 \mathrm{~mm}$ to $\leq 6 \mathrm{~mm}$ & 65 & 65 & 49 & 71 & 39 & 17 & 55 & 72 & 61 \\
\hline$>6 \mathrm{~mm}$ & 28 & 11 & 2 & 25 & 3 & 1 & 37 & 11 & 6 \\
\hline Number of sites & 88 & 88 & 88 & 96 & 96 & 96 & 80 & 80 & 80 \\
\hline
\end{tabular}

${ }^{a}$ Among the groups $(p<0.003)$; ${ }^{b}$ significance within each group $(p<0.05)$ and CAL: clinical attachment level, SRP: scaling and root planning.

(GII) of pockets. Marked improvement was observed at $\mathrm{T} 2$, with shallower pockets at $93 \%, 97 \%$, and $73 \%$ of sites in GI, GII, and GIII, respectively ( $\mathrm{p}<0.003)$.

\section{Clinical attachment level}

The mean CAL values are shown in Table 2. At T0, the average CAL value was $6.07 \mathrm{~mm}$, with no significant difference among groups. Overall mean clinical attachment gains were $4.98 \mathrm{~mm}$ at $\mathrm{T} 1$ and $4.37 \mathrm{~mm}$ at T2. GII showed significant gains after the first and second applications, whereas GI showed a gain only after the first application $(\mathrm{p}<0.05)$. GII showed the highest average gain in CAL between $\mathrm{T} 0$ and T2 $(2.54 \mathrm{~mm})$, with a significant difference from the gain achieved in GIII $(\mathrm{p}<0.003)$.

The difference of clinical attachment gain assessed by sites expressed as percentages is presented in Table 4. At T0, averages of 7\% of sites in GI and GIII and $4 \%$ of sites in GII had PPDs of $4 \mathrm{~mm}$. All groups had the largest proportions of sites in the 5 to $\leq 6 \mathrm{~mm}$ category. At T2, significant numbers of sites had improved from deep to shallow pockets (49\% in GI, $85 \%$ in GII, and 32\% in GIII, respectively; $\mathrm{p}<0.003$ ).

\section{Bleeding on probing}

Mean BOP values for all groups and timepoints are provided in Table 2. At $\mathrm{T} 0$, average BOP values were similar in all groups. BOP showed marked improvement between $\mathrm{T} 0$ and $\mathrm{T} 2$ in all groups $(p<0.05)$, with the greatest average reduction $(84 \%)$ observed in GII $(p<0.05)$. BOP decreased in a similar way in all groups, with no significant difference. At T1, it had decreased by two times in all groups; at T2, it had decreased by five, six, and four times, respectively, in GI-GIII. Thus, the greatest reduction occurred in all groups after the second gel application or control treatment.

The BOP values found by sites was also expressed as a percentage (Table 5). At T1 it decreased 2, 4 and 2 times for GI, GII, and GII, respectively. At $\mathrm{T} 2$, it decreased 3, 16 and 2 times, respectively. This meaning that, the reductions at $\mathrm{T} 2$ for GII were greater. 
Table 5. Bleeding on probing (BOP) response of the subjects treated with scaling and root planning (SRP) + 10\% DOX GEL (GI), $10 \%$ DOX/ $\beta$-cyclodextrin + SRP GEL (GII) and SRP (GIII), according to values at baseline (TO), 30 days (T1) and 60 days (T2), as well as mean of alterations by sites expressed as percentage.

\begin{tabular}{|c|c|c|c|c|c|c|c|c|c|}
\hline Bleeding on probing (BOP) & & G। & & & G॥ & & & G III & \\
\hline Response & T0 & $\mathrm{T} 1$ & T2 & TO & $\mathrm{T} 1$ & T2 & T0 & $\mathrm{Tl}$ & $\mathrm{T} 2$ \\
\hline Positive & 45 & 23 & 7 & 62 & 16 & 1 & 61 & 30 & 14 \\
\hline$\Delta \mathrm{TO}-\mathrm{T} 2$ & & 38 & & & $61^{a}$ & & & 47 & \\
\hline Number of sites & & $\mathrm{n}=88$ & & & $\mathrm{n}=96$ & & & $\mathrm{n}=80$ & \\
\hline
\end{tabular}

aSignificance within each group $(p<0.05)$. BOP: bleeding on probing, SRP: scaling and root planning.

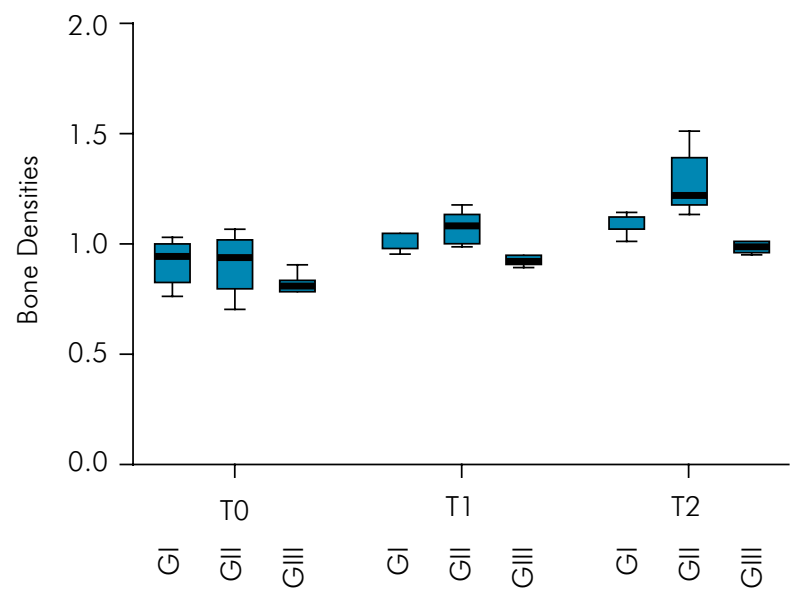

Figure 2. Boxplot of evaluation of measurements of bone densities obtained from radiographic of the subjects treated, between group, Scaling and Root Planning (SRP) + 10\% DOX gel (GI), SRP + 10\% DOX/ $\beta$-cyclodextrin gel (GII) and SRP (GIII), at TO (initial RX), T1 (RX 60 days after TO) and T2 (RX 18 months after TO).

\section{Visible plaque index}

Mean VPI values for all groups and timepoints are presented in Table 2. The VPI improved markedly between $\mathrm{T} 0$ and $\mathrm{T} 2$ in all groups $(\mathrm{p}<$ $0.05)$, decreasing by 5,6 , and 8 times in GI-GIII, respectively, comparing $\mathrm{T} 1$ with $\mathrm{T} 2$ the reduction was of 2 times in all groups. Thus, the greatest reductions were observed at $\mathrm{T} 1$ in all groups. Comparing the groups, there was no significant association between the groups in relation with plaque control, although GIII had the highest average reduction of VPI but this difference was not significant.

\section{Radiographic density}

The results of the comparative radiographic evaluation of bone density in GI and GII are presented in Figure 2. Bone density increased over time in both groups. However, when evaluated the results intragroup of GII between $\mathrm{T} 0$ and $\mathrm{T} 2$ showed a significant increase in bone density $(\mathrm{p}<0.05)$, but there was no significant difference inter-group in relation to the type of gel applied.

\section{Discussion}

Decreased PPD and gains in CAL are the main clinical measures used to assess the success of any periodontal treatment. ${ }^{25}$ Any periodontal pocket reduction or clinical attachment gain after drug administration represents a real clinical benefit and may reduce the need for additional surgical interventions. In addition, periodontal maintenance therapy should be performed with aim of preventing periodontitis recurrence, ${ }^{7}$ and the prolonged delivery of antibacterial agents can prevent recolonization after SRP ${ }^{26}$.

In the present study, all PPD values had decreased at $\mathrm{T} 2$ in relation to $\mathrm{T} 0$, with the greatest reduction observed in GII. GI and GII showed significant reductions in PPD at $\mathrm{T} 1$ and $\mathrm{T} 2$. Thus, the reapplication of DOX gels contributed to the final PPD results, especially in GII. Initially, most pockets were shallow or moderately deep. After 60 days, significant proportions of pockets had become shallow. From the clinical point of view, this result translates into periodontal health for subjects. Mendes et al. ${ }^{14}$ reported the reduction of PPD from 7-8 $\mathrm{mm}$ to $4 \mathrm{~mm}$, with accompanying clinical attachment gain which substantially improved the quality of life of individuals with periodontitis.

In the present study, the CAL increased significantly in all groups, with better results observed in the experimental group than in the control group. 
However, GII showed the greatest mean gain between T0 and T2 (42\% vs. $25 \%$ in GI and $17 \%$ in GIII). These results demonstrate that the reapplication of DOX gels contributed to the final CAL results in GI and GII, and especially in GII. CAL gains were greatest when analyzed by site, with significantly shallower pockets at $\mathrm{T} 2$.

The use of $10 \%$ DOX gel yielded a better clinical response at SRP-treated sites as other studies reported (Javali and Vandana ${ }^{27}$ and Ahamed et al. ${ }^{28}$ Jacomazzi et al. ${ }^{29}$ ). Their clinical results of those studies showed reduced PPD during the first 60 days and CAL gains only in the first 30 days. PPD reductions and CAL gains were obtained in the present study, especially in patients treated with $10 \%$ DOX $/ \beta$-CD gel. This result was greater than in other studies with similar designs and longer evaluation times. ${ }^{30,31}$

Bleeding on probing points to the success or the failure in periodontal treatment, because reveals the presence of inflammation of the pocket..$^{32} \mathrm{In}$ the present study, BOP decreased considerably and similarly in all groups, but without significant difference. The highest reductions occurred after the second application (T2) $(p<0.05)$ (Table 2). GII had the highest mean reduction (84\%) and by sites, was 16 times higher in T2 ( $<$ <0.05) (Table 5). One possible reason for this better result is that the inclusion of DOX in $\beta-C D$ may have prolonged the anti-inflammatory local effect of DOX, decreased the inflammatory markers, such as prostaglandin and MMPs, modulating the host response. DOX has been efficient in restricting these enzymes in minimal doses without developing bacterial resistance, for this reason, it is considered the most potent inhibitor of MMPs. Studies also reported substantial reductions in BOP and concluded that adjunct treatment is more effective compared to mechanics alone. ${ }^{33,34}$

VPI presented a strong reduction in all groups $(\mathrm{p}<0.05)$ (Table 2). The GIII (SRP) presented the highest mean reduction $(75 \%)$, but without significant difference. These results corroborate with Wennstrom et al. ${ }^{35}$ and Javali and Vandana ${ }^{27}$. These authors attributed the improvements observed to BOP and VPI to the adequate maintenance of oral hygiene. Besides, coronary polishing was performed to remove the supragingival biofilm, before each collection of clinical parameters. According to Deo et al., it is well established that the organization of the supragingival biofilm may block the distribution of the drug and inactivate the pharmacological action. Thus, the removal of this biofilm before the gel application could promote greater DOX efficacy. ${ }^{36}$

DOX concentrates on tissues, including the bone microenvironment, and also has an osteogenic effect. For these reasons, it has been used in the treatment of bone diseases. ${ }^{4,6}$ In the present study, the evaluation of bone density in the GI and GII radiography performed at T0 (initial RX), T2 (RX 60 days)) and T3 (RX 18 months) shows an increase in bone density, over time, in all groups, with no significant difference between them. However, GII showed a statistically significant increase in bone density between $\mathrm{T} 0$ and $\mathrm{T} 2$. They associated increased proliferation of osteoblasts with DOX / $\beta C D$ compared to free DOX. Agarwal and Gupta also found no significant difference in the periodontal repair of the infra-bony defects between the groups treated with or without free DOX, both groups showed significant improvements in the parameters. ${ }^{37}$ However, better results were obtained in the DOX-treated group, there were greater bone density and less crest resorption.

Previous studies have also shown that the therapeutic use of this tetracycline at low concentrations acts as a promoter of the proliferation of osteoblastic cells. $^{38}$ The results of Park et al. showed that when preosteoblasts were cultured in the presence of $10 \%$ DOX, there was an increase in alkaline phosphatase activity and resulted in increased calcium and mineral deposits. ${ }^{4}$

It can be inferred that the possible reasons for better results of this study were the reapplication of the gels and the inclusion of DOX in $\beta C D$. Soskolone showed that the frequency and time of contact with the subgingival microbiota is important because the increased turnover of the crevicular fluid in the periodontitis facilitates the faster diffusion of the drug from the gels, ${ }^{38}$ unless they become more viscous and less susceptible to hydrolysis. ${ }^{11}$

In spite of the results observed, other clinical trials of local release of antimicrobials are necessary for addition to the traditional treatments with longitudinal 
monitoring, investigating the need for reapplications. As well as the formulation of an application protocol, that could contribute to a greater acceptance of the association of local antimicrobials with the mechanical control of biofilm in patients with periodontitis.

In this study, the gel showed double slow delivery systems of DOX and inclusion compound with $\beta C D$. Through the local delivery of DOX it is possible to increase and to prolong the local action of the active principle. ${ }^{3,14}$ Besides, the anti-inflammatory effects of DOX may promote increased bone density. The best results after the second application reinforce the need for the presence of the drug at the target site for longer. The $10 \%$ DOX included in $\beta$-CD gel associated with SRP showed a significant improvement in periodontal clinical parameters $(\mathrm{PPD}, \mathrm{CAL}$, and $\mathrm{BOP}$ ) and VPI, providing additional benefits to the SRP alone. There was an increase in bone density over time in all groups. The molecular inclusion of doxycycline into $\beta-C D$ in gel is a relatively simple technology for local application in periodontitis showed satisfactory results.

\section{Acknowledgments}

This study was partially supported by the Coordination for the Improvement of Higher Education Personnel (CAPES), Brazil, National Council for Scientific and Technological Development (CNPq) Brazil, and the State of Minas Gerais Research Foundation (FAPEMIG).

\section{References}

1. Drisko CL. Periodontal debridement: still the treatment of choice. J Evid Based Dent Pract. 2014 Jun;14 Suppl:33-41.e1. https://doi.org/10.1016/i.jebdp.2014.02.007

2. Jepsen K, Jepsen S. Antibiotics/antimicrobials: systemic and local administration in the therapy of mild to moderately advanced periodontitis. Periodontol 2000. 2016 Jun;71(1):82-112. https://doi.org/10.1111/prd.12121

3. Nickles K, Scharf S, Röllke L, Dannewitz B, Eickholz P. Comparison of two different sampling methods for subgingival plaque: subgingival paper points or mouthrinse sample? J Periodontol. 2017 Apr;88(4):399-406. https://doi.org/10.1902/jop.2016.160249

4. Park JB. Effects of doxycycline, minocycline, and tetracycline on cell proliferation, differentiation, and protein expression in osteoprecursor cells. J Craniofac Surg. 2011 Sep;22(5):1839-42. https://doi.org/10.1097/SCS.0b013e31822e8216

5. Castro MM, Rizzi E, Prado CM, Rossi MA, Tanus-Santos JE, Gerlach RF. Imbalance between matrix metalloproteinases and tissue inhibitor of metalloproteinases in hypertensive vascular remodeling. Matrix Biol. 2010 Apr;29(3):194-201. https://doi.org/10.1016/i.matbio.2009.11.005

6. Khandan A, Ozada N, Karamia E. Novel microstructure mechanical activated nanocomposites for tissue engineering applications. J Bioeng Biomed Sci. 2015;5:143.

7. loannou I, Dimitriadis N, Papadimitriou K, Vouros I, Sakellari D, Konstantinidis A. The effect of locally delivered doxycycline in the treatment of chronic periodontitis. A clinical and microbiological cohort study. J Oral Maxillofac Res. 2011 Jan; (4):e1.

8. Holmes SG, Still K, Buttle DJ, Bishop NJ, Grabowski PS. Chemically modified tetracyclines act through multiple mechanisms directly on osteoclast precursors. Bone. 2004 Aug;35(2):471-8. https://doi.org/10.1016/j.bone.2004.02.028

9. Sandhya YP, Prabhuji ML, Chandra RV. Comparative evaluation of the efficacy of $10 \%$ doxycycline hyclate in the periodontal treatment of smokers: a clinical and microbiological study. Oral Health Prev Dent. 2011;9(1):59-65.

10. Uskokovic V. Nanostructured platforms for the sustained and local delivery of antibiotics in the treatment of osteomyelitis. Crit Rev Ther Drug Carrier Syst. 20 15; 32(1):1-59.https://doi.org/10.1615/CritRevTherDrugCarrierSyst.2014010920.

11. Mombelli A, Samaranayake LP. Topical and systemic antibiotics in the management of periodontal diseases. Int Dent J. 2004 Feb;54(1):3-14. https://doi.org/10.1111/j.1875-595X.2004.tb00246.x

12. Pattnaik S, Panigrahi L, Murthy RS. Periodontal muco-adhesive formulations for the treatment of infectious periodontal diseases. Curr Drug Deliv. 2007 Oct;4(4):303-23. https://doi.org/10.2174/156720107782151214

13. Gupta R, Pandit N, Aggarwal S, Verma A. Comparative evaluation of subgingivally delivered 10\% doxycycline hyclate and xanthan-based chlorhexidine gels in the treatment of chronic periodontitis. J Contemp Dent Pract. 2008 Nov;9(7):25-32. https://doi.org/10.5005/jcdp-9-7-25

14. Mendes AB, Fittipaldi JA, Neves RC, Chacra AR, Moreira Junior ED. Prevalence and correlates of inadequate glycaemic control: results from a nationwide survey in 6,671 adults with diabetes in Brazil. Acta Diabetol. 2010 Jun;47(2):137-45. https://doi.org/10.1007/s00592-009-0138-z 
15. Moura LA, Ribeiro FV, Aiello TB, Duek EA, Sallum EA, Nociti Junior FH, et al. Characterization of the release profile of doxycycline by PLGA microspheres adjunct to non-surgical periodontal therapy. J Biomater Sci Polym Ed. 2015;26(10):573-84 . https://doi.org/10.1080/09205063.2015.1045249

16. Garrett S, Adams DF, Bogle G, Donly K, Drisko CH, Hallmon WW, et al. The effect of locally delivered controlled-release doxycycline or scaling and root planing on periodontal maintenance patients over 9 months. J Periodontol. 2000 Jan;71(1):22-30. https://doi.org/10.1902/jop.2000.71.1.22

17. Yang R, Chen JB, Xiao CF, Liu ZC, Gao ZY, Yan SJ, et al. Inclusion complex of GA-13316 with $\beta$-cyclodextrin: preparation, characterization, molecular modeling, and in vitro evaluation. Carbohydr Polym. 2014 Oct;111:655-62. https://doi.org/10.1016/i.carbpol.2014.05.021

18. American Academy of Periodontology Task Force Report on the Update to the 1999 Classification of Periodontal Diseases and Conditions. J Periodontol. 2015 Jul;86(7):835-8. https://doi.org/10.1902/jop.2015.157001

19. Sato S. [In vivo evaluation of the effects of a slow release metronidazole device for treatment of periodontal pockets: clinical and microbiological parameters in an animal model] [thesis]. Ribeirão Preto: Faculdade, Universidade de São Paulo; 2010. Portuguese.

20. Ainamo J, Bay I. Problems and proposals for recording gingivitis and plaque. Int Dent J. 1975 Dec;25(4):229-35.

21. Silness J, Löe H. Periodontal disease in pregnancy. II: Correlation between oral hygiene and periodontal condition. Acta Odontol Scand. 1964;22(1):121-35. https://doi.org/10.3109/00016356408993968

22. Sener E, Cinarcik S, Baksi BG. Use of fractal analysis for the discrimination of trabecular changes between individuals with healthy gingiva or moderate periodontitis. J Periodontol. 2015 Dec;86(12):1364-9. https://doi.org/10.1902/jop.2015.150004

23. White SC, Rudolph DJ. Alterations of the trabecular pattern of the jaws in patients with osteoporosis. Oral Surg Oral Med Oral Pathol Oral Radiol Endod. 1999 Nov;88(5):628-35. https://doi.org/10.1016/S1079-2104(99)70097-1

24. Sindeaux R, Figueiredo PT, Melo NS, Guimarães AT, Lazarte L, Pereira FB, et al. Fractal dimension and mandibular cortical width in normal and osteoporotic men and women. Maturitas. 2014 Feb;77(2):142-8. https://doi.org/10.1016/i.maturitas.2013.10.011

25. Priyanka N, Kalra N, Saquib S, Kudyar N, Malgaonkar N, Jain H, et al. Clinical and microbiological efficacy of $3 \%$ satranidazole gel as a local drug delivery system in the treatment of chronic periodontitis: A randomized, controlled clinical trial. Contemp Clin Dent. 2015 Jul-Sep;6(3):364-70. https://doi.org/10.4103/0976-237X.161891

26. Jain N, Jain GK, Javed S, Iqbal Z, Talegaonkar S, Ahmad FJ, et al. Recent approaches for the treatment of periodontitis. Drug Discov Today. 2008 Nov;13(21-22):932-43. https://doi.org/10.1016/i.drudis.2008.07.010

27. Javali MA, Vandana KL. A comparative evaluation of atrigel delivery system (10\% doxycycline hyclate) Atridox with scaling and root planing and combination therapy in treatment of periodontitis: A clinical study. J Indian Soc Periodontol. 2012 Jan;16(1):43-8. https://doi.org/10.4103/0972-124X.94603

28. Ahamed S, Jalaluddin M, Khalid I, Moon N, Shaf TK, Ali FM. The use of controlled release locally delivered 10\% doxycycline hyclate gel as an adjunct to scaling and root planing in the treatment of chronic periodontitis: clinical and microbiological results. J Contemp Dent Pract. 2013 Nov;14(6):1080-6. https://doi.org/10.5005/ip-journals-10024-1455

29. Jacomazzi AM, Silva CO, Lima AF. Clinical evaluation of $10 \%$ doxycycline hyclate application in non-responsive periodontal sites. R. Periodontia. 2006;16(4):28-33.

30. Gürkan A, Emingil G, Çınarcık S, Berdeli A. Post-treatment effects of subantimicrobial dose doxycycline on clinical parameters and gingival crevicular fluid transforming growth factor-betal in severe, generalized chronic periodontitis. Int J Dent Hyg. 2008 May;6(2):84-92. https://doi.org/10.1111/i.1601-5037.2007.00268.x

31. Eickholz P, Kim TS, Bürklin T, Schacher B, Renggli HH, Schaecken MT, et al. Non-surgical periodontal therapy with adjunctive topical doxycycline: a double-blind randomized controlled multicenter study. J Clin Periodontol. 2002 Feb;29(2):108-17. https://doi.org/10.1034/i.1600-051x.2002.290204.x

32. Matuliene G, Pjetursson BE, Salvi GE, Schmidlin K, Brägger U, Zwahlen M, et al. Influence of residual pockets on progression of periodontitis and tooth loss: results after 11 years of maintenance. J Clin Periodontol. 2008 Aug;35(8):685-95. https://doi.org/10.1111/j.1600-051X.2008.01245.x

33. Reddy MS, Geurs NC, Gunsolley JC. Periodontal host modulation with antiproteinase, anti-inflammatory, and bone-sparing agents. A systematic review. Ann Periodontol. 2003 Dec;8(1):12-37. https://doi.org/10.1902/annals.2003.8.1.12

34. Emingil G, Gürkan A, Atilla G, Berdeli A, Cinarcik S. Adjunctive low-dose doxycycline therapy effect on clinical parameters and gingival crevicular fluid tissue plasminogen activator levels in chronic periodontitis. Inflamm Res. 2006 Dec;55(12):550-8. https://doi.org/10.1007/s00011-006-6074-2

35. Wennström JL, Newman HN, MacNeill SR, Killoy WJ, Griffiths GS, Gillam DG, et al. Utilisation of locally delivered doxycycline in non-surgical treatment of chronic periodontitis. A comparative multi-centre trial of 2 treatment approaches. J Clin Periodontol. 2001 Aug;28(8):753-61. https://doi.org/10.1034/j.1600-051X.2001.280806.x

36. Deo V, Ansari S, Mandia S, Bhongade M. Therapeutic efficacy of subgingival delivered doxycycline hyclate as an adjunct to non-surgical treatment of chronic periodontitis. J Oral Maxillofac Res. 2011 Apr;2(1):e3. https://doi.org/10.5037/jomr.2011.2103 
37. Agarwal A, Gupta ND. Combination of bone allograft, barrier membrane and doxycycline in the treatment of infrabony periodontal defects: A comparative trial. Saudi Dent J. 2015 Jul;27(3):155-60. https://doi.org/10.1016/i.sdentj.2015.01.003

38. Gomes PS, Fernandes MH. Effect of therapeutic levels of doxycycline and minocycline in the proliferation and differentiation of human bone marrow osteoblastic cells. Arch Oral Biol. 2007 Mar;52(3):251-9. https://doi.org/10.1016/j.archoralbio.2006.10.005

39. Soskolne WA. Subgingival delivery of therapeutic agents in the treatment of periodontal diseases. Crit Rev Oral Biol Med. 1997;8(2):164-74. https://doi.org/10.1177/10454411970080020501 